\title{
CRISPR-induced RASGAP deficiencies in colorectal cancer organoids reveal that only loss of NF1 promotes resistance to EGFR inhibition
}

\author{
Jasmin B. Post ${ }^{1,2}$, Nizar Hami ${ }^{1,2}$, Alexander E.E. Mertens ${ }^{1,2}$, Suraya Elfrink ${ }^{1,2}$, \\ Johannes L. Bos ${ }^{1,2}$ and Hugo J.G. Snippert ${ }^{1,2}$ \\ ${ }^{1}$ Center for Molecular Medicine, Section Molecular Cancer Research, University Medical Center Utrecht, Utrecht, The \\ Netherlands \\ ${ }^{2}$ Oncode Netherlands, Institute Netherlands, Office Jaarbeurs Innovation Mile, Utrecht, The Netherlands \\ Correspondence to: Hugo J.G. Snippert, email: H.J.G.Snippert@umcutrecht.nl \\ Keywords: NFI; RASGAP; anti-EGFR therapy resistance; cancer progression; colorectal cancer \\ Received: December 12, $2018 \quad$ Accepted: February 01, $2019 \quad$ Published: February 15, 2019 \\ Copyright: Post et al. This is an open-access article distributed under the terms of the Creative Commons Attribution License 3.0 \\ (CC BY 3.0), which permits unrestricted use, distribution, and reproduction in any medium, provided the original author and source \\ are credited.
}

\section{ABSTRACT}

Anti-EGFR therapy is used to treat metastatic colorectal cancer (CRC) patients, for which initial response rates of $\mathbf{1 0 - 2 0 \%}$ have been achieved. Although the presence of HER2 amplifications and oncogenic mutations in KRAS, NRAS, and BRAF are associated with EGFR-targeted therapy resistance, for a large population of CRC patients the underlying mechanism of RAS-MEK-ERK hyperactivation is not clear. Loss-of-function mutations in RASGAPs are often speculated in literature to promote CRC growth as being negative regulators of RAS, but direct experimental evidence is lacking. We generated a CRISPR-mediated knock out panel of all RASGAPs in patient-derived CRC organoids and found that only loss of NF1, but no other RASGAPs e.g. RASA1, results in enhanced RAS-ERK signal amplification and improved tolerance towards limited EGF stimulation. Our data suggests that NF1-deficient CRCs are likely not responsive to anti-EGFR monotherapy and can potentially function as a biomarker for CRC progression.

\section{INTRODUCTION}

Colorectal cancer (CRC) is one of the most common cancers and the third leading cause of worldwide cancer deaths (IARC). The use of monoclonal antibodies (moAbs) targeting the epidermal growth factor receptor (EGFR), such as cetuximab and panitumumab, together with chemotherapy has shown a clinical benefit for the treatment of patients with metastatic CRC (mCRC) [1-3]. The binding of these antibodies to the extracellular domain of the EGFR inhibits downstream activation of the RASMEK-ERK signaling pathway, thereby inhibiting cell proliferation and survival $[4,5]$. Treatment with EGFR targeting moAbs resulted in initial response rates of $10-20 \%$ in mCRC patients [1], but it soon became clear that tumors with activating mutations in KRAS showed resistance to EGFR inhibition [2, 3, 6]. Moreover, the treatment of patients with mutant KRAS colorectal tumors with EGFR inhibitors seemed to aggravate disease progression [3]. Therefore these patients are now being excluded from EGFR targeted therapy $[7,8]$.

RAS proteins act as molecular switches that cycle between inactive GDP-bound and active GTP-bound states. Active GTP-bound RAS can stimulate a large variety of downstream signaling cascades, including the mitogen activated protein kinase (MAPK) and phosphatidylinositol3-kinase (PI3K) pathways, to promote proliferation, migration and survival. The activation of RAS is tightly regulated by guanine nucleotide exchange factors (GEFs) and GTPases activating proteins (GAPs). GEFs accelerate the dissociation of GDP from RAS, whereas GAPs enhance the intrinsic rate of GTP hydrolysis of RAS [9]. Activating mutations in KRAS are identified in approximately $35-50 \%$ of mCRC patients, resulting in the constitutive downstream activation of MEK and ERK $[9,10]$. It is thought that KRAS oncogenic mutations are 
early events in cancer progression, potentially even at the onset of tumorigenesis, as they are frequently found in both early and late stages of CRC [10-12]. In agreement with this, genomic studies have highlighted that the MAPK signaling pathway is often aberrantly activated in colorectal tumors [13-16]. However, in contrast to pancreatic cancers, where oncogenic KRAS mutations are found in $90 \%$ of the cases $[17,18]$, a large population of CRC patients carry tumors that are wild type for KRAS. Indeed, other oncogenic mutations in the MAPK signaling pathway, such as mutations in NRAS, BRAF, or HER2 amplifications, have been identified in CRC and are implicated in tumor progression [19-23]. Nevertheless, for at least $25 \%$ of $\mathrm{mCRC}$ patients the underlying cause of aberrant MAPK pathway activation remains unknown [19-22].

In this regard, RASGAPs that act as negative regulators of RAS signaling are frequently implicated in tumorigenesis. In the human genome, ten functional RASGAP genes have been identified. Genetic analysis of tumor samples only identified a significant number of inactivating mutations in the RASGAPs neurofibromin (NF1) and RASA1 (p120GAP), suggesting that these two RASGAPs can function as tumor suppressors. Moreover, ongoing sequencing efforts of larger patient cohorts may increase the detection of low abundant loss-of-function mutations in several other RASGAPs [24, 25].

Loss-of-function mutations in NF1 are frequently associated with a large variety of cancers, such as melanoma [26-29], leukemia [30-32], glioblastoma [33], and lung cancer [25]. Moreover, multiple studies have linked NF1 activity to RAS and ERK activity [28, 29, 33-36], including its role in therapy resistance upon targeted inhibition of the MAPK pathway in melanoma [28, 29, 36, 37] and lung cancer [38]. Inactivating mutations and deletions in the RASA1 gene have also been detected in a number of cancers, such as lung squamous carcinoma [39], stomach, esophagus [40], leukemia [41], and head and neck [25] cancer, but its role as a tumor suppressor is less well defined.

In line with their molecular function, a suggestive tumor suppressive role for RASGAPs in CRC has been proposed based on association studies [42-46], as well as knock-down experiments in cell lines [47, 48]. However, the debate whether indeed all RASGAPs can mediate CRC progression beyond EGF dependence remains ongoing, in particular since the lack of direct loss-of-function data regarding RASGAPs in CRC models.

Here, using CRISPR-mediated knock out lines in patient-derived CRC organoids that are otherwise wild type for the RAS pathway, we investigate the role of RASGAPs in CRC progression and in relation to EGFR signaling. Surprisingly, in contrast to widely accepted assumptions, but in line with overall mutation frequencies, we show that only the loss of NF1, but no other RASGAPs, can act as an amplifier of MAPK signaling. As such, NF1-deficiency contributes to CRC progression by minimizing its dependence on EGF-ligand stimulated MAPK signaling.

\section{RESULTS}

\section{Low abundant mutation frequencies for RASGAPs in CRC}

Strong activating mutations of RAS pathway effectors tend to occur in a mutually exclusive manner, most pronounced for oncogenic mutations in either RAS or BRAF.

Corresponding with reported activity of NF1 as a tumor suppressor and negative regulator of RAS in lung adenocarcinomas [38], truncating mutations in NF1 tend to be mutual exclusive with activating mutations in $R A S$ and $B R A F$ (TCGA) in these tumors (Figure 1A). Although the sample size of this lung adenocarcinoma cohort is too small to obtain reliable numbers for low abundant deletion and inactivating mutation frequencies in most other RASGAP genes, inactivating mutations in RASA1 seem, like NF1, mutual exclusive with other activating mutations of the MAPK signaling pathway (Figure 1A).

The mutually exclusivity between loss-of-function mutations in NF1 and oncogenic mutations in $R A S$ and $B R A F$ is also observed in melanoma patients (TCGA) (Figure 1B). However, a number of melanoma patients do have tumors that present both truncating mutations in $N F 1$ as well as oncogenic mutations in $B R A F$. Interestingly, all of the BRAF mutations that show co-occurrence with NF1 truncating mutations, both lung adenocarcinoma and melanoma samples, do not present the V600E hotspot mutation. Indeed, the non-V600E activating mutations in $B R A F$ only induce weak oncogenic BRAF activity [49], suggesting that co-occurrence with NF1 loss, is required to obtain sufficient levels of RAS-ERK signaling. The frequency of inactivating alterations in the other RASGAP genes in this cohort of melanoma patients is again infrequent and too low to indicate their potential role in cancer development and progression (Figure 1B).

In contrast to lung adenocarcinoma and melanoma patients, the numbers of inactivating mutations in colorectal adenocarcinoma patients are low in all RASGAP genes (TCGA), including NF1 (Figure 1C). For CRC, low abundant mutation frequencies of RASGAPs might be the result of tissue-specific mechanisms of MAPK pathway activation and questions whether the loss of RASGAPs can actually play a substantial role in tumor progression of CRCs. Alternatively, other mechanisms affecting RASGAP protein levels, such as post-translational modifications affecting protein stability as well as gene silencing, can also account for decreased RASGAP activity, but this data is not present in sufficient quality and quantity to provide us more insight on functional mutually exclusivity $[25,40]$.

Thus, whereas mutual exclusivity of NF1loss, in combination with previous experimental data 
A

Lung adenocarcinoma (TCGA, Nature 2014)

KRAS

NRAS

HRAS

BRAF

NF1

RASA1

RASA2

RASA3

RASA4

RASAL1

RASAL2

RASAL3

SYNGAP1

DAB2IP

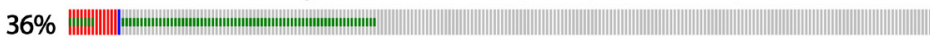
3\% |

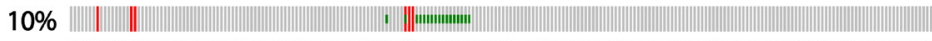
9\%

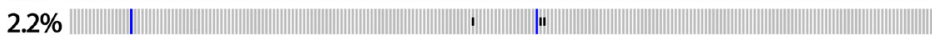

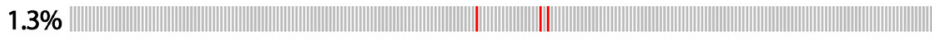

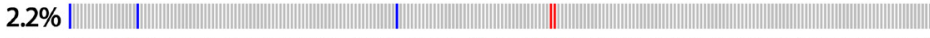
|

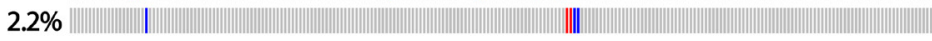
8\%

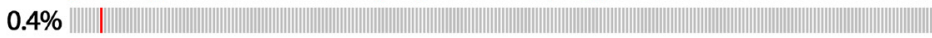

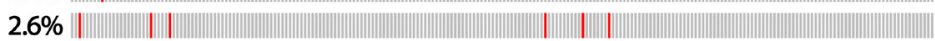
|

$$
(n=230)
$$

B

KRAS

NRAS

HRAS

BRAF

NF1

RASA1

RASA2

RASA3

RASA4

RASAL1

RASAL2

RASAL3

SYNGAP1

DAB2IP

Skin cutanous melanoma (TCGA, provisional)

| 3\% |

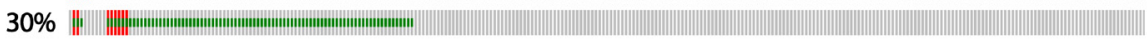
| |

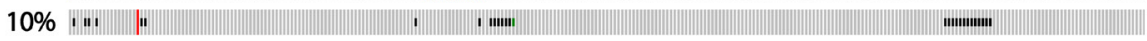

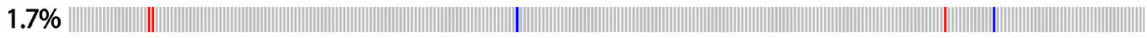

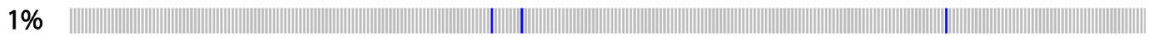
1.4\%

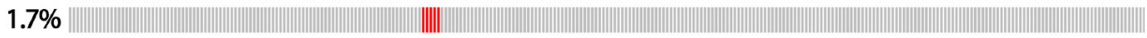
| |

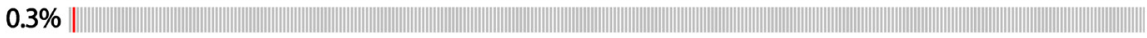
| |

$$
(n=287)
$$

\begin{tabular}{|c|c|}
\hline & Colorectal adenocarcinoma (TCGA, Nature 2012) \\
\hline KRAS & 42\% | \\
\hline NRAS & 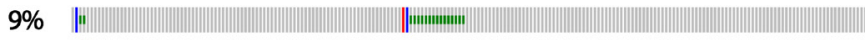 \\
\hline HRAS & 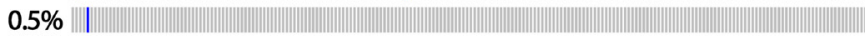 \\
\hline BRAF & $10 \%$ \\
\hline NF1 & 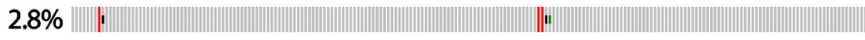 \\
\hline RASA1 & 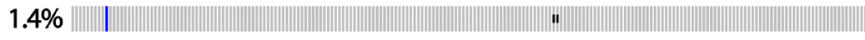 \\
\hline RASA2 & 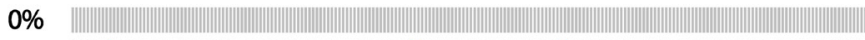 \\
\hline RASA3 & 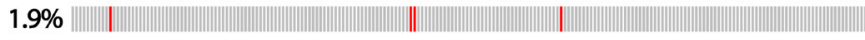 \\
\hline RASA4 & 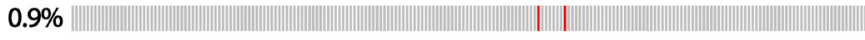 \\
\hline RASAL1 & 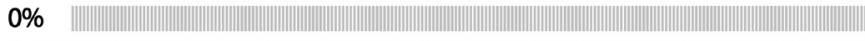 \\
\hline AL2 & 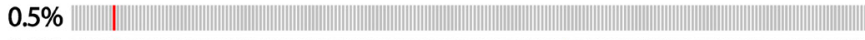 \\
\hline RASAL3 & 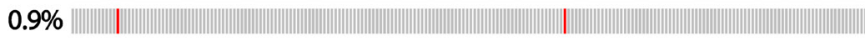 \\
\hline SYNGAP1 & 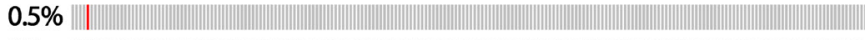 \\
\hline AB2IP & ס \\
\hline
\end{tabular}

C

$$
(n=212)
$$

Genetic alterations

|Amplification |Deep Deletion

I Missense Mutation (putative driver) IInframe Mutation (putative driver) ITruncating Mutation (putative driver)

Figure 1: The occurrence of RASGAP and oncogenic mutations in the MAPK signaling pathway in lung adenocarcinoma, melanoma and colorectal adenocarcinoma. The distribution of driver mutations and copy number alterations in KRAS, NRAS, HRAS, BRAF, and RASGAPs in (A) lung adenocarcinoma $(n=230)$, (B) skin cutaneous melanoma $(n=287)$ and $(\mathbf{C})$ colorectal adenocarcinoma $(n=212)$ from TCGA datasets are shown. Data were extracted through cBioPortal and presented as OncoPrint. Color coding indicates mutation type: red, homozygous amplification; blue, homozygous deletion; green, missense mutation; brown, inframe putative driver mutation; black, truncating mutation. Left, mutation percentage. 
$[26,28,29,36,38]$, support NF1 as a strong oncogenic driver in lung adenocarcinoma and melanoma, the general oncogenic role of RASGAP deficiency in CRC remains inconclusive.

\section{A CRISPR-mediated RASGAP knock out screen identifies NF1 as the only RASGAP which depletion enables enhanced tumor growth and EGF-independent survival}

To circumvent the lack of patient-data regarding loss of RASGAP expression, we set out to test the function of RASGAPs in CRC in an experimental setting. For this we utilize a patient-derived tumor organoid (P18T) with loss-of-function mutations in the WNT (APC) and TP53 pathway, but that is wild type for the RAS pathway and as such requires EGF-mediated growth factor signaling for growth and survival [50]. With the exception of RASAL3, which shows specific expression in the hematopoietic lineage in mice and humans (Supplementary Figure 1A), we identified the other RASGAPs at similar expression levels (Figure 2A) [51, 52]. To investigate whether loss of RASGAPs enables EGF-independent tumor cell growth and survival in CRCs, we depleted the activity of each RASGAP separately in P18T organoids using CRISPRinduced knock outs by targeting Cas9 cleavage activity against the conserved arginine finger in the catalytic GAP domain (Figure 2B) [53, 54]. The generation of knock outs was confirmed by DNA sequencing analysis of multiple monoclonal RASGAP knock out organoids (Supplementary Figure 1B). Subsequently, the population of RASGAP deficient CRC organoids were intermittently cultured in the absence of EGF signaling activity (EGF depleted growth medium containing afatinib, a small molecule inhibitor that targets the tyrosine kinase receptors EGFR, HER2 and HER4) (Figure 2B).

Surprisingly, we found that only the loss of NF1 GAP activity, but not of the other RASGAPs, resulted in a significant organoid growth upon intermittent EGFR inhibition (Figure 2C). In contrast to autonomous KRAS mutations, inactive NF1 did not result in complete EGF independence as organoid sizes remained small (but survived) upon continuous EGFR inhibition. However, elevated growth was observed under culture conditions with minimal EGFR stimulation (data not shown).

Since small sized organoids were observed for most conditions, including the negative control, we labelled all living organoids at the end point with calcein green to perform accurate measurements of number and size of organoids. Again, it illustrates that the number of organoids that are significantly larger in size is only observed after loss of NF1 activity in relation to the other RASGAP knock out organoids (Figure 2C and Supplementary Figure 1C). Importantly, to exclude the possibility that this observation was influenced by patient specific effects, we performed a similar experiment in which we targeted upstream exons or the GAP domains of $N F 1$ and RASA1 in engineered tumor organoids that are also deficient in APC and TP53 (commonly referred to as tumor progression organoid 2 (TPO2)) [55]. Reassuring, a similar phenotype was observed in the TPO2 organoids, in which again only the loss of NF1 resulted in an increased outgrowth of large organoids as compared to control (Supplementary Figure 2A and 2B).

Together, these results indicate that only loss of NF1 activity promotes the outgrowth of CRCs upon limited EGFR signaling. The lack of participation by other RASGAPs is surprising, but consistent with the nonredundant and tissue-specific functions of RASGAPs [56].

\section{Generation of NF1 and RASA1 knock out organoid lines independent of phenotypic selection}

As a tumor suppressive role has predominantly been suggested for both NF1 and RASA1 [25, 40], we continued to investigate both their function in CRC. Since the CRISPR/Cas9-induced truncating mutations in the GAP domain, which lies central in the protein sequence, may have resulted in the generation of dominant-negative versions, we also generated complete $N F 1$ and $R A S A 1$ knock out lines in the CRC background of P18T (Supplementary Figures 3 and 4). Underscoring the role of NF1 deficiency in CRC progression upon EGFR signal inhibition, all outgrowth clones of NF1 were true knock outs (10/10), in contrast to only half of the RASA1 clones (7/14). Indeed, our selection method on phenotype could potentially result in the positive selection of undesired off-target mutations, which alone or together with NF1 or RASA1 inactivating mutations may lead to EGF independence and increased cell proliferation. Therefore, additional knock outs were generated without phenotypic selection, but by means of integration of puromycin selection cassettes via homologous recombination (Figure 3A) [57].

Indeed, this strategy led to the successful generation of non-functional $N F 1$ and RASA1 genes independent of selection through EGFR inhibition (EGFRi) (Figure $3 \mathrm{~B}$ and $3 \mathrm{D}$ ). Of note, the puromycin selection cassette was properly integrated into the NF1 gene body (Supplementary Figure 5A), accompanied by the introduction of small indel mutations in the 'secondary' allele (Figure 3B). Although the selection cassette was also integrated into the genome of RASAI knock out organoids (Supplementary Figure 5B), we could not confirm its exact integration site, probably due to its random genomic integration. Most importantly, we did confirm introduction of small indel mutations at both alleles of the RASA1 gene (Figure 3D). Moreover, Western blot analysis of the different clones showed complete loss of NF1 and RASA1 protein in P18T CRC organoids (Figure 3C and 3E, and Supplementary Figure 5C). As we were able to generate multiple RASGAP knock out clones, we continued 
A

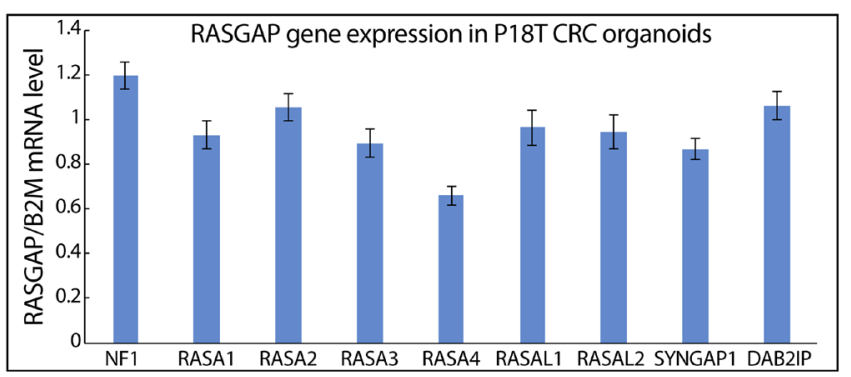

\section{B}
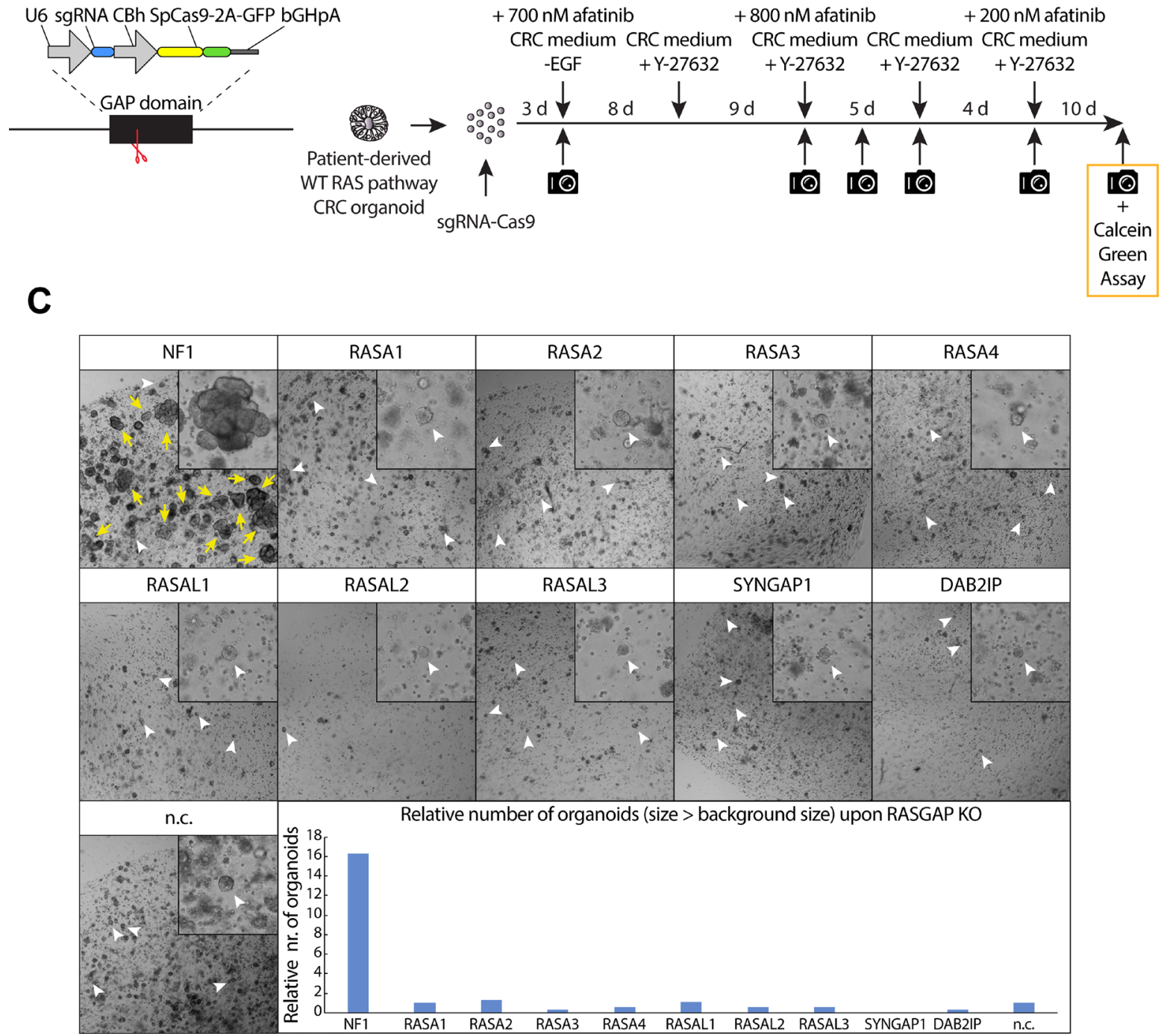

Figure 2: CRISPR screen against RASGAPs in patient-derived CRC organoids reveals increased growth and EGFindependent survival upon loss of NF1 GAP activity. (A) The mRNA expression level of 9 RASGAPs containing an active GAP domain was analyzed in P18T organoids using qPCR. The relative expression of each RASGAP gene was normalized to the $B 2 M$ housekeeping gene (representative from $n=3$ independent experiments). (B) Left; schematic representation of expression plasmid containing both an U6 promoter-driven sgRNA and a CBh promoter-driven SpCas9-2A-GFP was used to target the RASGAP domain. Right; schematic overview of the RASGAP knock out screen in P18T patient-derived CRC organoids that are wild type for the RAS signaling pathway. (C) P18T CRC organoids in selection medium that have been transfected with indicated sgRNAs and Cas9. White arrow heads indicate representative background organoids. Yellow arrows indicate successful organoids that are significantly larger than background. Bar graph depicts the relative number of organoids with a size larger than background organoids as determined in the negative control. Area of alive RASGAP knock out organoids was measured using calcein green assay (see Materials and Methods). 
A
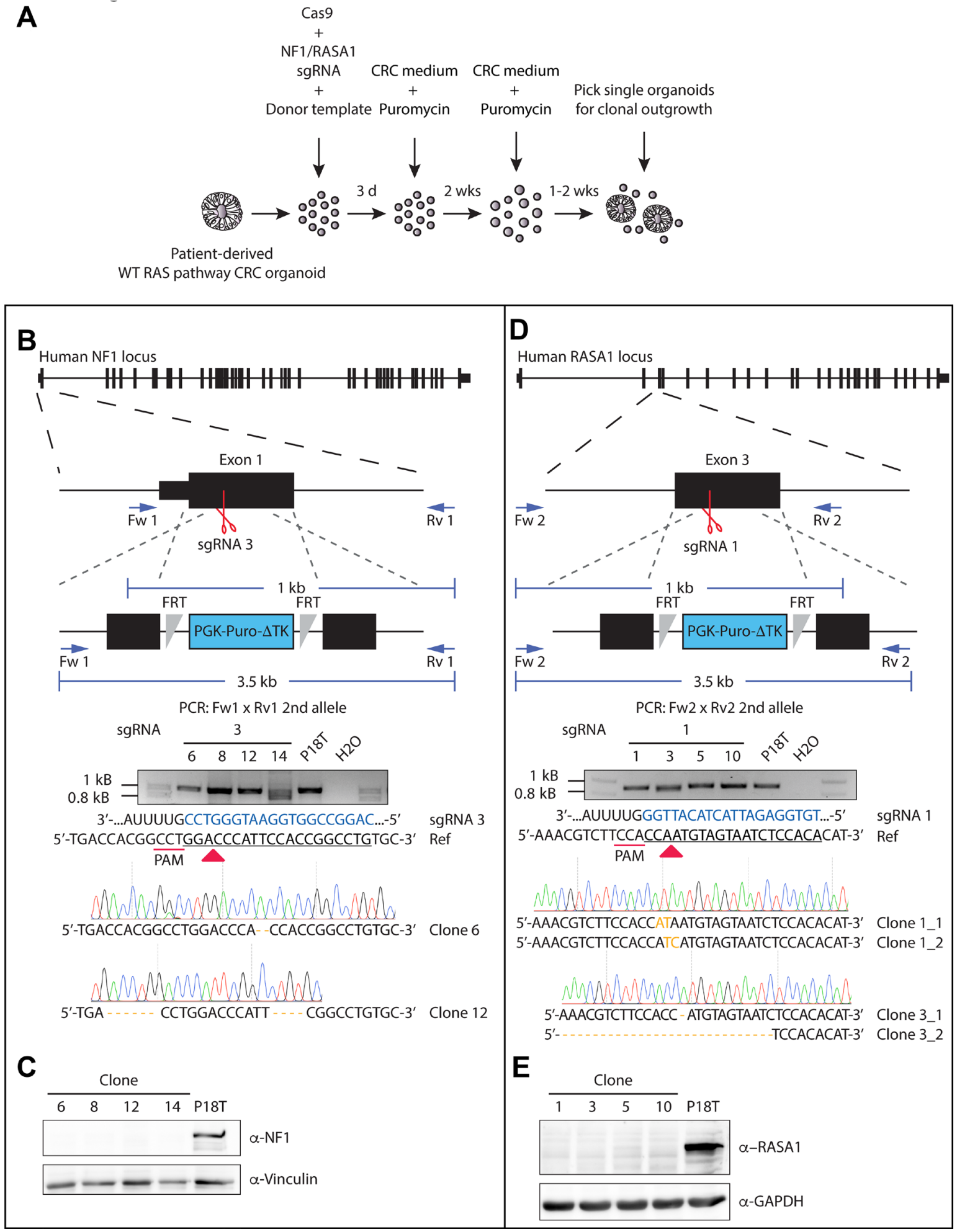

Figure 3: Generation of CRISPR-mediated NF1 and RASA1 knock out in patient-derived CRC organoids. (A) Selection strategy to generate NF1 and RASA1 knock out organoids after CRISPR-mediated homologous recombination. (B, D) Genetic strategy to target the $N F 1$ and RASA1 locus for homologous directed repair via the CRISPR/Cas9. The structure of the $N F 1$ and RASA1 gene and the targeted exon is depicted at the top. Black boxes illustrate exons, separated by introns. Red scissors show sgRNA-generated double stranded breaks. Blue arrows illustrate PCR primer pairs. The agarose electrophoresis gel shows the $\sim 1 \mathrm{~kb}$ PCR product of the allele that was repaired by NHEJ of NFI (Clone \# 6 and 12) and RASA1 (Clone \# 1 allele 1 and 2, Clone \# 2 allele 1 and 2) in selected clones. Sanger sequencing indicate the introduced small indels per clone. Nonmatching bases are shown in orange. Regions of the sgRNA complementary to the protospacer (underlined) are shown in blue. Red arrow heads indicate cleavage sites. (C, E) Western blot analysis for NF1 and RASA1 presence in the indicated organoid lines. 
working with two different clones of each RASGAP knock out to exclude clonal effects.

\section{NF1 deficiency, but not RASA1, causes intrinsic EGF-independency}

First, we validated whether loss of NF1, but not RASA1, induced intrinsic EGF independence for CRC organoid survival by examining the effect of afatinib (EGFR/HERi) treatment on organoid viability by microscopy. Therefore, 5 days after trypsinization the parental P18T organoids, as well as the NF1 and RASA1 knock out organoid cultures, were filtered to homogenize their size and subsequently cultured with afatinib or DMSO (control) for 72 hours (Figure 4A). In agreement with our RASGAP knock out screen (Figure 2), complete loss of NF1 indeed resulted in a slight increase in EGF independence in terms of cell survival, showing healthy but small organoids after EGFRi treatment. In contrast, the parental P18T, as well as the RASA1 knock out lines, predominantly died in the presence of EGFR inhibition (Figure 4B).

\section{Loss of NF1 expression enhances basal RAS- ERK activity in CRC organoids}

For both NF1 and RASA1 it has been demonstrated that they can affect RAS and ERK activity in various cell lines $[35,38,45]$. To investigate the molecular mechanism that underlies increased tumor growth and EGF-independent survival upon loss of NF1 expression, we analyzed the activity of the RAS-MAPK signaling pathway.

Consistent with the phenotypes of our RASGAP knock out lines, only the loss of NF1 expression in CRC organoids resulted in enhanced ERK activation under basal conditions (Figure 5A and Supplementary Figure 6A), which was further verified by quantification (Supplementary Figure 7A).

Whereas inhibition of EGF signaling clearly reduced the levels of active (phosphorylated) ERK in all three organoid types (i.e. P18T, NF1 and RASA1 KOs) after 1 hour of afatinib treatment, a substantial reactivation of ERK was observed in alive NF1 knock out organoids after 72 hours of afatinib treatment (Figure 5A and 5B). Importantly, similar reactivation effects albeit with different kinetics were observed in different NF1 $\mathrm{KO}$ clones (Figure 5B and Supplementary Figure 6A), explaining their enhanced survival upon EGFR inhibition.

Since the predicted function of NF1 GAP activity is to enhance the intrinsic GTP hydrolysis rate of GTPbound RAS, we examined the amounts of active, GTPbound RAS that are present in the absence of NF1. As a positive control, we also analyzed RAS-GTP levels in a P18T organoid line in which an activating mutation in KRAS (G12D) was introduced by CRISPR technology [58]. In comparison with the parental P18T line, loss of NF1 clearly enhanced RAS-GTP levels at basal conditions to similar levels as observed in KRAS mutant P18T organoids. However, whereas a substantial fraction of GTP-bound RAS was detected in oncogenic mutant KRAS organoids after 24 hours of EGFR inhibition, this was not observed in NF1 knock out organoids (Figure 5C, Supplementary Figures 6B, and 7B). This discrepancy on RAS-GTP loading may very well be explained by the fact that NF1, in contrast to self-autonomous oncogenic KRAS, acts as an amplifier of RAS-mediated signaling. Therefore, the effect of NF1-loss can only manifest itself in the presence of RAS activating signals, i.e. in the presence of incoming EGF signaling. Indeed, in the RASGAP CRISPR screen we observed that the largest differences in organoid growth and viability were obtained in the presence of minimal EGF signaling.

As expected by the sensitivity of RASA1 knock out organoids for EGFR signal inhibition, loss of RASA1 did not enhance or sustain RAS-MAPK signaling in case of inhibition, nor under normal growth conditions (Figure 5C, Supplementary Figures 6A, 6B and 7A, 7B). Subsequently, we analyzed protein levels of both NF1 and RASA1 in the RASA1 knock out organoid lines to investigate whether upregulated expression of NF1 acts as a compensation mechanism, but we did not observe any differences in the knock-out lines as compared to wild type P18T (Figure 5D). To explore whether other RASGAPs compensate for the loss of RASA1 activity, we examined the mRNA expression levels of the other RASGAPs in RASA1 and NF1 knock out organoids. In addition to some clonal variability, we detected slight increased expression for most RASGAP genes in the case of NF1 or RASA1 deficiency (Figure 5E). However, no clear candidates could be identified which expression level is suggestive for a redundant function to RASA1 deficiency and might have explained a compensatory mechanism that prevents aberrant RAS activation.

Intriguing, while it has been demonstrated that all RASGAPs contain an active GAP domain, our data only identifies NF1 as a bona fide amplifier of RAS-mediated MAPK signaling in patient-derived CRC organoids.

\section{NF1-deficient CRC organoids show enhanced organoid survival and growth upon release of RAS-MAPK pathway inhibition}

A recent study showed that NF1 mutations correlated with a poor response to cetuximab-based EGFR inhibition and decreased progression free survival of mCRC patients [46]. Resistance to targeted therapy is often the result of residual RAS-ERK signaling activity [59]. In agreement, we detected enhanced organoid survival and residual ERK activity in NF1-deficient CRC organoids upon long-term EGFR inhibition with afatinib. Therefore, as NF1 loss predominantly amplifies RAS-MAPK signaling activity in unperturbed conditions, we hypothesized that the phenotype of NF1 deficiency might manifest itself most 
A

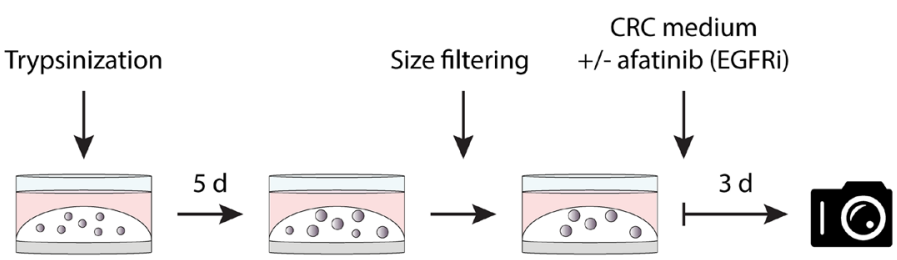

B
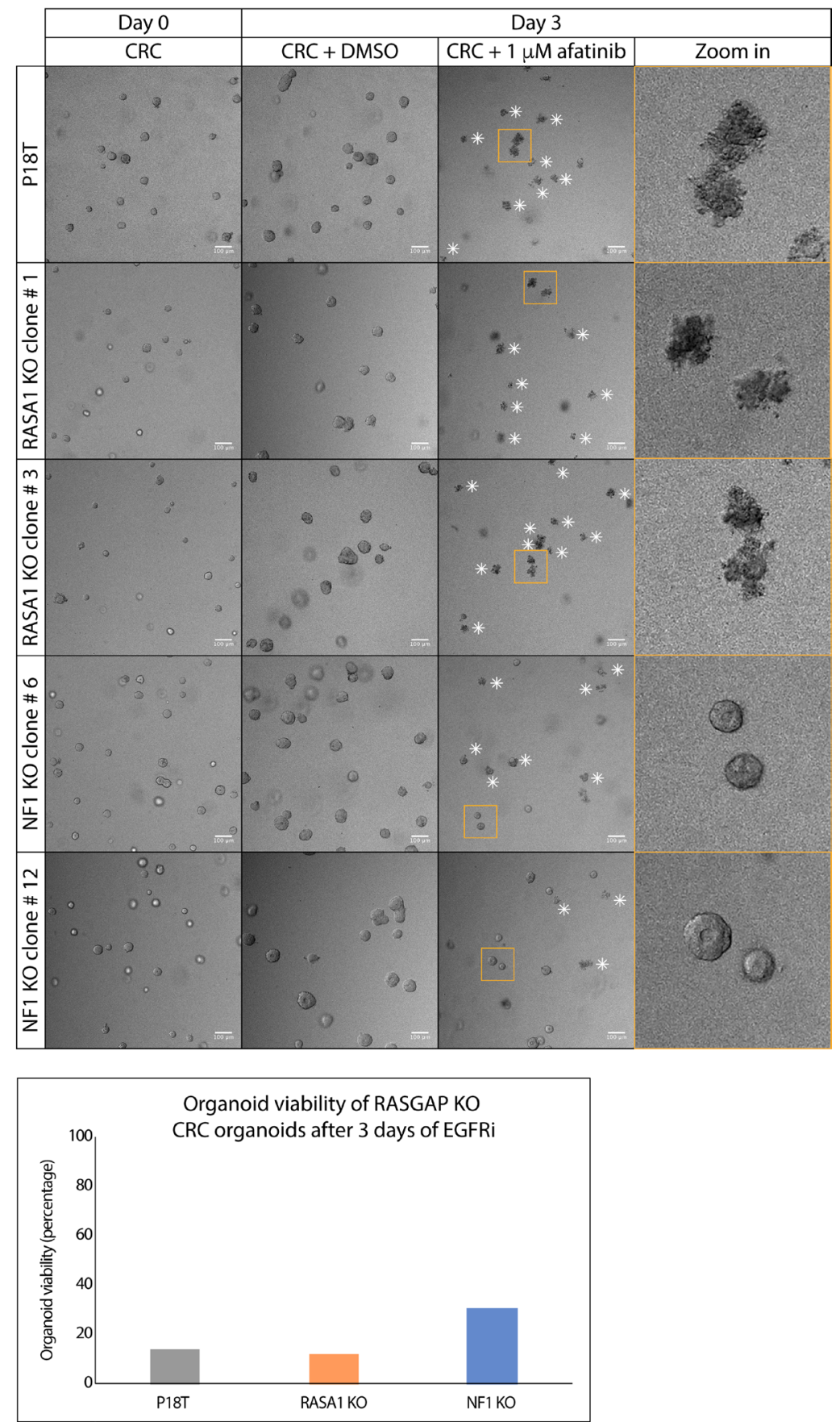

Figure 4: Puromycin selected NF1 knock out CRC organoids show insensitivity to EGFR inhibition. (A) A schematic overview illustrating the strategy to score sensitivity of NF1 and RASA1 knock out organoids of similar size treated with colorectal cancer (CRC) medium containing either DMSO or $1 \mu \mathrm{M}$ afatinib (EGFRi) for 72 hours. (B) Representative pictures of the parental patient-derived CRC organoids P18T and P18T RASA1 (clone \# 1 and \# 3) or NF1 (\# 6 and \# 12) knock out organoids prior (day 0) and after 72 hours of DMSO or $1 \mu \mathrm{M}$ afatinib treatment (Day 3). White asterisks indicate dead organoids. Scale bars, $100 \mu \mathrm{M}$. Bar graph depicts the percentage of living organoids (out of 100 organoid counts) based on morphology. 
A

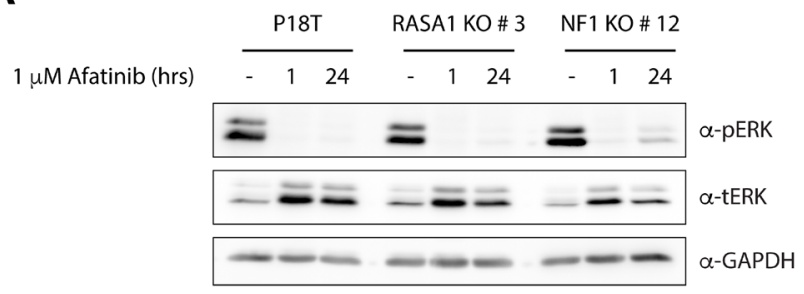

B
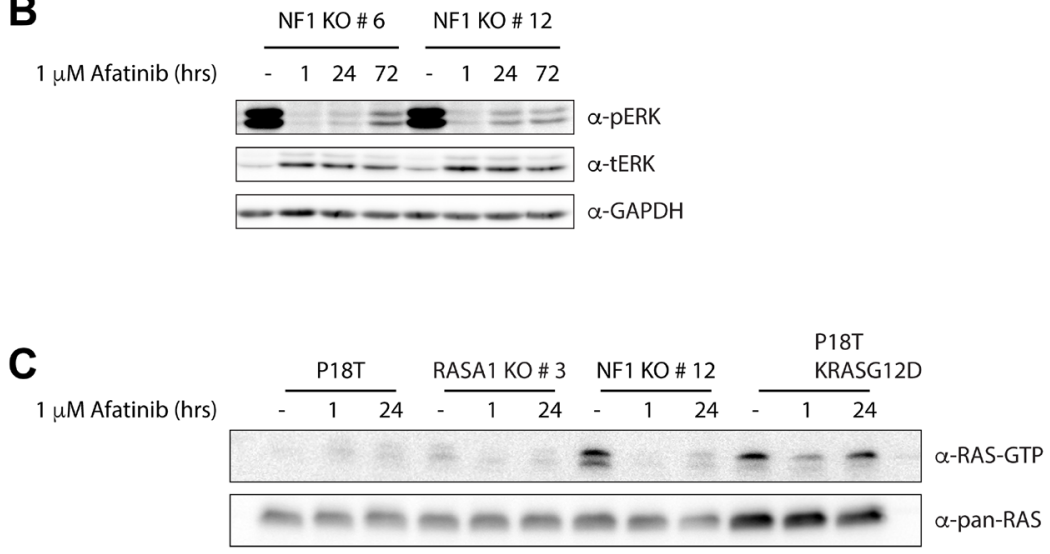

D

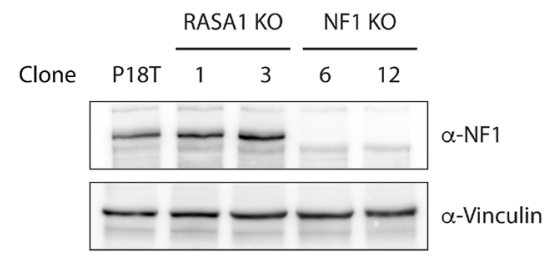

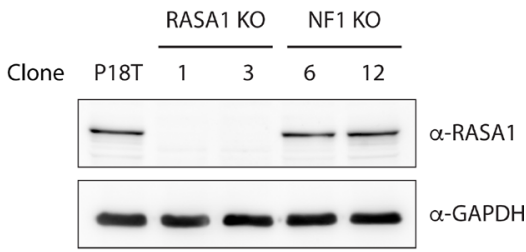

E

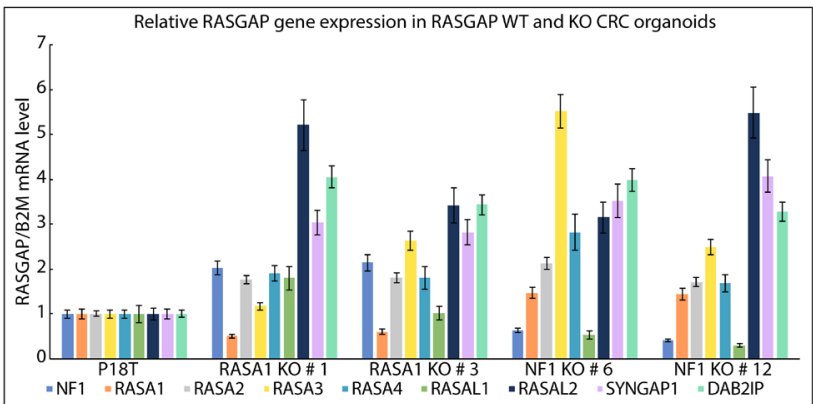

Figure 5: Puromycin selected NF1 knock out CRC organoids show enhanced RAS and ERK activation. (A) In comparison to P18T and P18T RASA1 ${ }^{\mathrm{KO}}$ (clone \# 3), predominantly P18T NF1 ${ }^{\mathrm{KO}}$ (clone \# 12) organoids show enhanced basal and reactivated ERK phosphorylation levels after $24 \mathrm{hr}$ treatment with CRC medium containing $1 \mu \mathrm{M}$ afatinib. Representative from $n=3$ independent experiments. (B) NF1-deficient organoids (clone \# 6 and \# 12) show residual ERK phosphorylation after treatment with CRC medium containing $1 \mu \mathrm{M}$ afatinib with varying kinetics. (C) Loss of NF1 (clone \# 12) leads to elevated levels of RAS activity (GTPloading) at basal conditions compared to P18T and P18T RASA1 ${ }^{\mathrm{KO}}$ (clone \# 3) CRC organoids. The presence of an oncogenic mutation in KRAS (P18T KRAS ${ }^{\text {G12D }}$ ) leads to elevated and sustained high levels of RAS activity (GTP-loading) at basal and in afatinib-treated conditions, respectively. RAS immunoblots from RAS pull-down assays are shown (RAS-GTP), together with a RAS immunoblot from total cell lysates as loading control. HRAS, KRAS, and NRAS isoforms are detected. Representative from $n=2$ independent experiments. (D) Immunoblots of P18T, P18T RASA1 ${ }^{\mathrm{KO}}$ (clone \# 1 and 3), P18T NF1 ${ }^{\mathrm{KO}}$ (clone \# 6 and 12) CRC organoids indicate that the loss of RASA1 does not result in elevated protein levels of NF1, and vice versa. Representative from $n=3$ independent experiments. (E) The relative expression levels of indicated RASGAPs genes that contain an active GAP domain were analyzed in P18T, P18T RASA1 ${ }^{\text {KO }}$ (clone \# 1 and 3), P18T NF1 ${ }^{\mathrm{KO}}$ (clone \# 6 and 12) CRC organoids using RT-PCR. The relative expression of each RASGAP gene was normalized to the $B 2 M$ housekeeping gene (representative from $n=3$ independent experiments). 
evidently upon the release of EGFR inhibition. In contrast, desired cytotoxicity upon targeted therapy should be achieved upon full RAS-MAPK signal inhibition.

To investigate this, we set up a drug screen to measure the phenotypic response of parental P18T, both RASGAP knock outs, as well as KRAS mutant P18T organoids, during and after mono- and combinatorial targeted therapies against the RAS-MAPK signaling pathway (Figure 6A).

In line with our previous results, NF1 knock out organoids show some resistance to EGFR-targeted therapy (afatinib) in comparison to wild type organoids, but not as evident as the resistance observed in KRAS mutant organoids (Figure 6B, Supplementary Figure 8A, 8B). Whereas the observed effects remain subtle for the monotherapies, combined inhibition of MEK (selumetinib) and EGFR/HER (afatinib) resulted in an improved cytotoxic response in NF1 knock out organoids (Figure 6B, Supplementary Figure 8A, 8B).

Most striking however, when organoids were released from targeted inhibition, a tremendous organoid outgrowth was observed in NF1-deficient organoids that was only matched by KRAS mutant organoids. In contrast, parental KRAS $^{\mathrm{WT}}$ and RASA1 knock out organoids remained small even upon drug withdrawal (Figure 6C and Supplementary Figure 8). In contrast to the autonomous KRAS ${ }^{\text {G12D }}$ mutation, the phenotype of NF1 deficiency manifests itself predominantly under challenging EGFR signaling conditions, but is not able to rescue complete inhibition of the MAPK signaling pathway. These result are consistent with observations in an in vitro and in vivo model of NF1-deficient lung adenocarcinoma treated with EGFR and MEK inhibitors [38]. Translating these results to a clinic setting suggests that NF1-deficient $\mathrm{mCRC}$ are able to show favorable responses towards targeted inhibition of the RAS-MAPK pathway, but only under strict full inhibitory conditions using combinatorial targeting strategies with ideally a continuous treatment regime.

\section{DISCUSSION}

Data analysis of patients with lung adenocarcinoma and melanoma show that of all RASGAPs only inactivating mutations in $N F 1$ tend to occur in a mutually exclusive manner with activating hotspot mutations in KRAS, NRAS and $B R A F$. This suggests that the loss of NF1 is sufficient to drive aberrant activity of the RAS-MAPK signaling pathway in the absence of other mutations in the RAS signaling pathway. However, the data is less clear for CRCs, in which the frequency of loss-of-function mutations in RASGAPs are very low, bringing into question whether the loss of RASGAPs plays an important role in CRC development and progression. Moreover, the identification of RASGAPs in large GWAS studies and RASGAP expression analysis studies has led to their family-wide association with tumorigenesis [39, 47, 48, 60-65], in contrast to mutation frequencies that mainly point to NF1 [25].
To end the debate, we set out to investigate the functional relationship between all RASGAPs and tumor growth in the presence and absence of EGFR signaling in colorectal tumors. Therefore, we performed a CRISPRmediated knock out screen to study RASGAPs with a functional GAP domain in patient-derived CRC organoids. Surprisingly, of all the potential RASGAPs, we identified that only the loss of NF1 resulted in increased tumor growth and EGF-independent cell survival. Importantly, our observations were made in multiple genetic backgrounds and by multiple genetic strategies. On the biochemical level, loss of NF1 results in enhanced RASERK activation but does require presence of active EGFR signaling to do so. Indeed, in contrast to autonomous KRAS $^{\text {G12D }}$, NF1 loss mainly acts as a signal amplifier. As such, NF1 deficient tumors remain vulnerable to targeted inhibition of the MAPK pathway, but only under complete inhibitory conditions. Under normal growth conditions, i.e. presence of EGF signals, NF1 deficiency might be responsible for aberrant MAPK signal activation in CRCs that are wild type for known MAPK driver genes.

Several studies have shown that the expression of NF1 is altered in a number of sporadic cancers $[25,40]$. Moreover, loss of NF1 expression has been observed in lung adenocarcinomas and melanomas that are resistant to treatment with EGFR [38] and BRAF [28, 29, 36, 37] inhibitors, respectively. Whereas reports on the frequency of genetic alterations of NF1 in CRC show varying results, a recent study associated mutant NF1 with tumor progression and anti-EGFR therapy resistance [46]. To our knowledge we are the first to present direct loss-offunction data that of all RASGAPs only the loss of NF1 promotes enhanced tumor growth and EGF-independent survival in CRC. Next generation sequencing studies identified that the NF1 gene is altered in approximately $5-6 \%$ of colorectal carcinomas [66]. Since loss of NF1 can also be accomplished via mechanisms other than loss-offunction mutations, such as epigenetic gene silencing or aberrant protein stability [33, 67], analysis of NF1 protein levels in tumor biopsies may be of importance to correctly stratify the patient population for targeted therapy against the MAPK signaling pathway.

Although enhancing RAS-ERK signaling during normal tumor growth conditions, NF1 deficiencies are not as dominant drivers of MAPK signaling activity as oncogenic versions of KRAS. As a result, patients with NF1 mutant CRCs are much more likely to respond to combinatorial targeting of the MAPK signaling pathway than RAS mutants in case full inhibition is achieved. In relation to mutational co-occurrence, it is conceivable that loss of NF1 can enhance otherwise weak activating mutations of the MAPK signaling pathway to reach optimal levels of pathway activation for efficient tumor growth [68].

To confirm the role of NF1 as an amplifier of the RAS effector, we also tried to determine the levels of RAS-ERK activation upon minimal perturbation of 


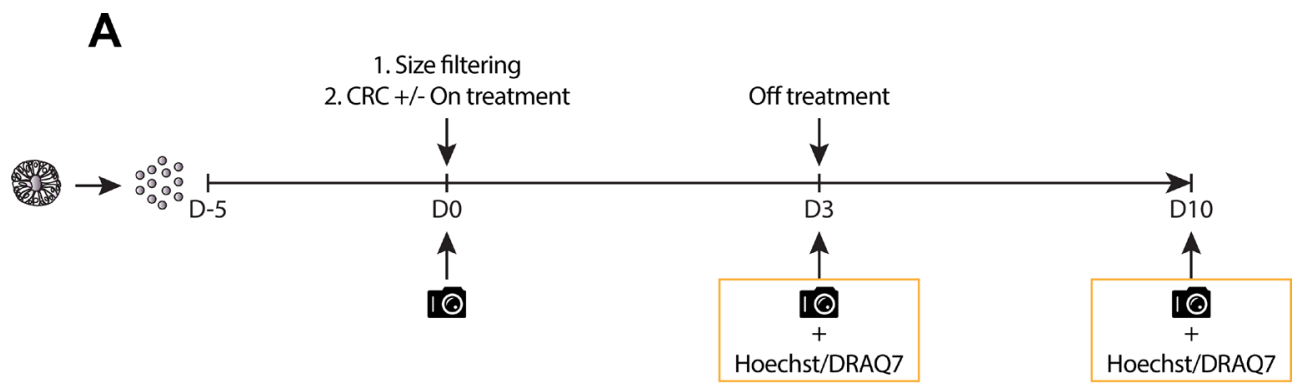

B

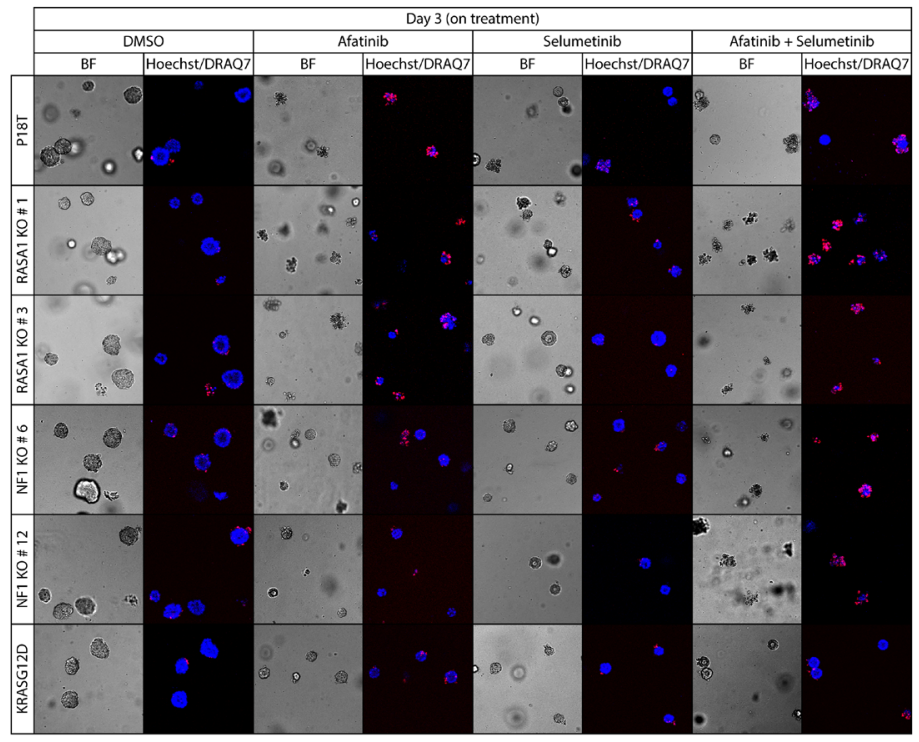

C

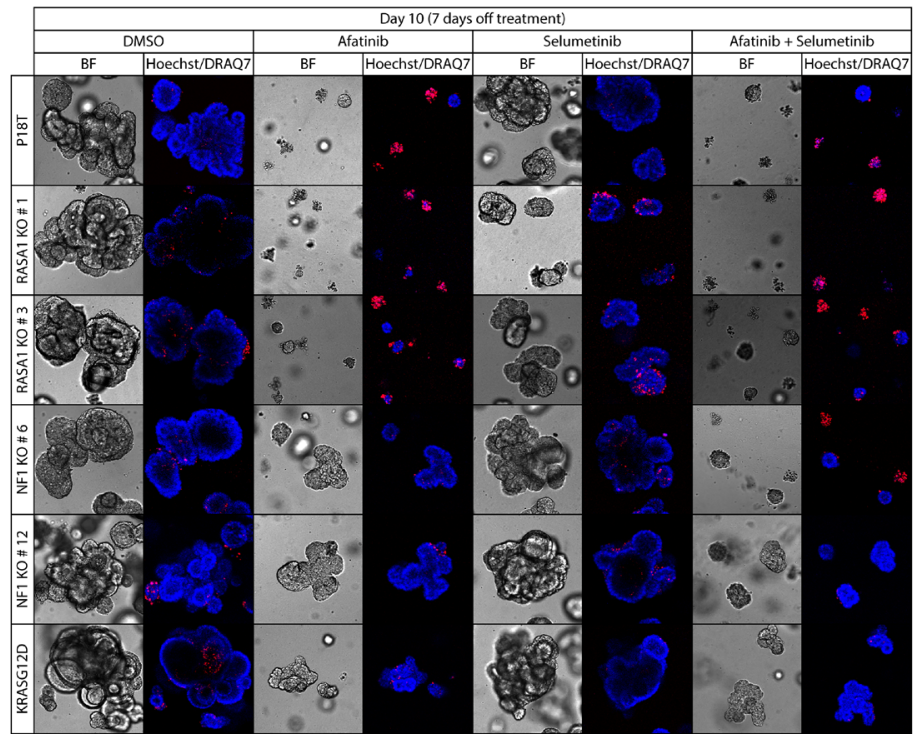

Figure 6: Puromycin selected NF1 knock out CRC organoids show enhanced organoid growth upon release of RAS-MAPK pathway inhibition. (A) A schematic overview illustrating the strategy to score sensitivity and outgrowth of P18T parental, RASGAP knock out, and oncogenic mutant KRAS organoids of similar size during and after treatment with colorectal cancer (CRC) medium containing either DMSO, $1 \mu \mathrm{M}$ afatinib (EGFRi), $1 \mu \mathrm{M}$ selumetinib (MEKi), or a combination of $1 \mu \mathrm{M}$ afatinib and 1 $\mu \mathrm{M}$ selumetinib. Organoid size and frequency of alive organoids was quantified after $72 \mathrm{hr}$ of drug treatment and after 7 days of drug withdrawal by phenotypic analysis. (B) Representative zoom-in pictures of the parental patient-derived CRC organoids P18T KRAS ${ }^{\mathrm{WT}}$, KRAS ${ }^{\text {G12D }}$, and P18T RASA1 (clone \# 1 and \# 3) or NF1 (\# 6 and \# 12) after 72 hours of DMSO or targeted drug treatment (on treatment). (C) Representative zoom-in pictures of the parental patient-derived CRC organoids P18T KRAS ${ }^{\mathrm{WT}}$, KRAS ${ }^{\mathrm{G} 12 \mathrm{D}}$, and P18T RASA1 (clone \# 1 and \# 3) or NF1 (\# 6 and \# 12) after 7 days of DMSO or drug withdrawal (off treatment). Hoechst and DRAQ7 was used to visualize nuclei and dead cells, respectively. 
EGFR signaling with low concentrations of afatinib. In contrast to P18T and RASA1 knock outs, enhanced levels of active RAS-ERK signaling, comparable to levels of KRAS mutants, was again observed at basal conditions in NF1 knock out organoids. However, elevated levels of active GTP-bound RAS proteins were challenging to detect under minimal perturbation of EGFR signaling, among others due to drug titration difficulties to achieve reduced but remaining EGFR activity, as well as different distribution of RAS proteins at the membrane under changing EGFR stimulation that can mask the effect of NF1 loss on the membrane pool [69].

Whereas several publications have proposed a tumor suppressor role for RASA1 in CRC [43-45], we did not observe elevated levels of RAS and ERK activity in RASA1 knock out organoids at basal conditions. Importantly, loss of RASA1 was not sufficient to promote EGF-independent survival. Moreover, the upregulated expression levels of other RASGAPs did not point to a clear candidate that could compensate for its loss. From a molecular perspective, it is not clear whether RASA1 is indeed a negative regulator of RAS in colon, or that the existing pool of NF1 or other RASGAPs is sufficient to compensate its absence. For instance, differences in the RAS binding groove have previously been identified between RASA1 and NF1, which have been attributed to higher RAS binding affinities for NF1 [53, 54]. Moreover, other studies have demonstrated that RASA1 may have increased activity toward R-RAS compared to other RAS proteins, thereby affecting RalA activity, but not PI3K or MAPK signaling [70, 71]. Our data, together with observations that ubiquitous loss of RASA1 in mice does not lead to spontaneous tumor formation, questions whether RASA1 functions as an essential tumor suppressor in the gut [72].

Together, using patient-derived CRC organoids, we reveal that of all RASGAPs with functional GAP domains, only NF1 deficiency promote cell survival and enhanced tumor growth upon challenging EGF signaling conditions in human CRC samples. On the basis of our data, we propose that NF1 protein levels should be determined in CRCs prior initiation of targeted therapy against the MAPK pathway. Patients with NF1-deficient tumors are likely to be unresponsive to anti-EGFR targeted monotherapy. However, on a positive note, we did observe that these tumors, unlike KRAS mutant colorectal tumors, are vulnerable towards combinatorial targeting strategies against the RAS-MAPK pathway.

\section{MATERIALS AND METHODS}

\section{Patient-derived organoid culture and maintenance}

The patient-derived organoids derived in this study were previously established and characterized (van de
Wetering et al., 2015 and Drost et al., 2015). Human CRC and TPO2 (APC-/-, TP53-/-) colon organoids were cultured as described previously (van de Wetering et al., 2015, Drost et al., 2015, Verissimo et al., 2016). Culture medium containen advanced DMEM/F12 medium (Invitrogen) with $1 \%$ Penicillin/Streptomycin $(\mathrm{P} / \mathrm{S}$, Lonza), 1\% Hepes buffer (Invitrogen) and 1\% Glutamax (Invitrogen), 20\% R-spondin conditioned medium, 10\% Noggin conditioned medium, 1x B27 (Invitrogen), $1.25 \mathrm{mM}$ n-Acetyl Cysteine (Sigma-Aldrich), 10 $\mathrm{mM}$ Nicotinamide (Sigma-Aldrich), $50 \mathrm{ng} / \mathrm{ml}$ EGF (Invitrogen), 500 nM A83-01 (Tocris), $10 \mu \mathrm{M} \mathrm{SB202190}$ (ApexBio) and $100 \mu \mathrm{g} / \mathrm{ml}$ Primorcin (Invitrogen). Organoids were splitted through Trypsin-EDTA (SigmaAldrich) treatment. Culture medium after splitting was supplemented with $10 \mu \mathrm{M}$ Y-27632 dihydrochloride. For selection of RASGAP knock out mutants, organoids were grown in culture medium containing $1-2 \mu \mathrm{M}$ puromycin or lacking EGF and containing $0.2-1.0 \mu \mathrm{M}$ of afatinib (Selleck Chemicals).

The Jurkat cells were cultured in RPMI 1640 medium supplemented with 10\% FBS, 1\% Penicillin/ Streptomycin (P/S, Lonza) and 1\% Glutamax (Invitrogen).

\section{Organoid transfection and genotyping}

The transfection protocol of P18T and TPO2 organoids was previously described in detail by Fujii et al. (2015). Three days after transfection, culture media plus Y-27632 was exchanged with selection medium. After puromycin selection, surviving clones were picked and subjected to genotyping to detect the presence of insertions and deletions.

For genotyping, genomic DNA was isolated using Viagen Direct PCR (Viagen). The presence of insertions or deletions in RASGAPs was verified by using the PCR product obtained using the following primers:

NF1_fw 5'-GACCCTCTCCTTGCCTCTTC-3', NF1_rv 5'-GGTGGCTCTGAAGCAGTTTC-3', RASA1_fw1 5'-GACTCTTCCTTTTCCTCCCG-3', RASA1_rv1 5'-G CAGTTTGGTGAGAGCCATG-3', RASA1 fw2 5'-GT TGGGCATTACTGTGCTG-3', RASA1_rv2 5' - GGTG GTGCAACTGGGTAAAG-3', NF1_fw GAP domain 5'-GTACACTGTTAAATCTCAGG-3', NF1_rv GAP domain 5'-AGAGGATGTGATCACAATTC-3', RASA1_ fw GAP domain 5'-GTCTTACAGAGTTAAGTCTG-3', RASA1_rv GAP domain 5'-GTATTACAGACAGGTGT AAC-3', RASA2_fw GAP domain 5'-CTTATGCCTTCT AGTATGTC-3', RASA2_rv GAP domain 5'-TGCTTCTA AAGTGTTCAGTC-3', RASA3_fw GAP domain 5'-GT GTTGACACAGGACGGTTC-3', RASA3_rv GAP domain 5'-GGAGTACACAGGGAACATC- -3 ', RASA4_fw GAP domain 5'-AGAACACTGGGAGGTG TTTG-3', RASA4_rv GAP domain 5'-CGAACTCCTG ACCTTAAGTG-3', RASAL1_fw GAP domain 5'-TGTG CACCTCCAGACAGTTG-3', RASAL1_rv GAP domain 5'-GACCATGCAGGAAGAGGTTC-3', 
RASAL2_fw GAP domain 5'-CAGCATTTCCAGGATG TCTG-3', RASAL2_rv GAP domain 5'-AGCAGTGTA TGCTGACAAGG-3', RASAL3 fw GAP domain 5'-GC CTAAGCATCAGCTACAAG-3', RASAL3_rv GAP domain 5'-GTCTTCAGGTTATTCCGGAG-3', SYNGAP1_fw GAP domain 5'-CACATCCTGCAGAGT ACAGG-3', SYNGAP1_rv GAP domain 5'-ACAAGAG GGTGTGGTCACAC-3', DAB2IP_fw GAP domain 5'-C ACCAGTTCTAGGCTCCTAC-3', DAB2IP_rv GAP domain 5'-ACTTGCTGGGATCCACTTCG-3'.

Products were sequenced using the following primers: NF1 exon 1 5'-CTTCCTTTCCTCCAGAGCCTG-3', RASA1 exon 1 5'-CACAAGCTGCCCTCTCCCTT-3', RASA1 exon 3 5'-CAAATAAACTTTGAGTGGTA-3', NF1 GAP domain 5'-GTACACTGTTAAATCTCAGG-3', RASA1 GAP domain 5'-GTACTTTCAACGCTGCAC-3', RASA2 GAP domain 5'-CCTTCCCATCAATAGATC-3', RASA3 GAP domain 5'-GTGTTGACACAGGACGGT TC-3', RASA4 GAP domain 5'-GAACACTGGAGTCGA AGTC-3', RASAL1 GAP domain 5'-CTGGAAGAATC ATGACTCC-3', RASAL2 GAP domain 5'-CCAGTGCG TCATGAAGATAC-3', RASAL3 GAP domain 5'-GTCT TCAGGTTATTCCGGAG-3', SYNGAP1 GAP domain 5'CACGAGATTGGGTTGTGC-3', DAB2IP GAP domain 5'-CTAGGTCTGGAATCCTAG-3'.

In addition, the CloneJET PCR Cloning Kit was used to confirm indel generation in NF1 knock outs \#1 and \#6 and of RASA1 knock outs \#1 and \#3.

The presence of the puromycin selection cassette was verified by using the PCR product obtained using primers:

Puro_1_fw 5'-GACCCTCTCCTTGCCTCTTC-3', Puro_1_rv 5'-GTTGGCGCCTACCGGTGG-3', Puro_2_fw 5'-ATGGGGACCGAGTACAAGCC-3', Puro_2_rv 5'-GTCGAAGATGAGGGTGAG-3'.

\section{Vector construction}

The CRISPR guide RNA (sgRNAs) were designed by an online CRISPR design tool (http://crispr.mit.edu). The sgRNA guide sequences used can be found in the Supplementary Materials (Supplementary Table 1). The sgRNAs used for the RASGAP knock out screen were cloned into a plasmid (px458) expressing both sgRNA and hCas9-2A-GFP as previously described (Ran et al., 2013).

For CRISPR-mediated homologous recombination the human codon-optimized Cas9 expression plasmid was obtained from Addgene (41815). The sgRNA-GFP plasmid was obtained from Addgene (41819) and used as a template for generating target specific sgRNAs as described in detail by Drost et al. (2015). For the generation of the donor template, genomic DNA from P18T organoids was used to PCR amplify the NF1 and RASA1 homology arms using high-fidelity Phusion Polymerase (New England BioLabs). The 5' homology arm of RASA1 spans the region Chr5:87331757-87332526, and the 3' homology arm spans the region Chr5:87332575-87333379. The 5' homology arm of NF1 spans the region Chr17:3109457431095323 , and the $3^{\prime}$ homology arm spans the region Chr17:31095361-31096136. The homology arms were cloned into a pBlueScript plasmid expressing a 3229bp AATPB:PGKpuroDtk selection cassette (Schwank et al., 2013).

\section{Western blot assay and RAS-GTP pull down}

Prior to cell lysis, organoids were incubated with $1 \mathrm{mg} / \mathrm{ml}$ dispase II (Invitrogen) for 10 minutes at $37^{\circ} \mathrm{C}$ to digest the BME. Western blot samples for NF1 and RASA1 protein levels were lysed using NETN buffer (50 mM Tris-HCL pH 8.0, 250 mM NaCl, 5 mM EDTA, $0.5 \%$ NP-40) containing Complete protease inhibitors (Roche). Western blot samples for phosphorylated ERK were lysed using RIPA buffer (50 mM Tris-HCL pH 8.0, $150 \mathrm{mM} \mathrm{NaCl}, 0.1 \%$ SDS, $0.5 \%$ Na-Deoxycholate, $1 \%$ NP-40) containing Complete protease inhibitors (Roche). Protein content was quantified using a BCA protein assay kit (Pierce ${ }^{\mathrm{TM}}$ ) and analyzed by Western blotting. Membranes were blocked and probed with antibodies directed against NF1 (RRID:AB_2149790), RASA1 (RRID:AB_303418), Vinculin RRID:ĀB_477629, a-tubulin (RRID:AB_477579), GAPDH (RRID:AB_2107445), pERK (RRID:AB_331646), and ERK (RRID:AB_390779).

Samples for RAS-GTP isolation were lysed using Ral lysis buffer (50 mM Tris-HCL pH 7.5, $200 \mathrm{mM} \mathrm{NaCl}$, $2 \mathrm{mM} \mathrm{MgCl} 2,10 \%$ glycerol, 1\% NP-40) containing Complete protease inhibitors (Roche). Lysates were normalized for protein levels using a BCA protein assay kit (Pierce ${ }^{\mathrm{TM}}$ ) and subsequently GTP-bound RAS was isolated via immunoprecipitation using recombinant RAS binding domain of RAF1 (RAF1-RBD). Protein lysates were run on SDS-PAGE gels and transferred to PVDF membranes (Millipore). Membranes were blocked and probed with antibodies directed against RAS (RRID:AB_397425). Organoid treatments: afatinib (Selleck Chemicals) $1 \mu \mathrm{M}$, $1 \mathrm{~h}$ and $24 \mathrm{~h}$ or DMSO.

\section{RNA isolation, cDNA preparation and qRT-PCR.}

Organoids were harvested in RLT lysis buffer and RNA was isolated using the Qiagen RNeasy kit (Qiagen) according to the manufacturer's instructions. Extracted RNA was used as a template for cDNA production using iScript $^{\mathrm{TM}}$ cDNA Synthesis Kit (Bio-Rad) according to the manufacturer's protocol. qRT-PCR was performed using FastStart Universal SYBR Green Master mix (Roche) according to the manufacturer's protocol. Results were calculated by using the relative standard curve method. Primer sequences:

B2M_fw 5'-GAGGCTATCCAGCGTACTCCA-3', B2M_rv 5'-CGGCAGGCATACTCATCTTTT-3', 
NF1_fw 5'-GGATCCTACCAGGTTAGAACCATC-3', NF1_rv 5'-AGCTTTATTCAGTAGGGAGTGGC-3', RASA1_fw 5'-AATGCAGGATCAAGAACAAG-3', RASA1_rv 5'-AAGGCATCCTTTGTTTTACG-3', RASA2_fw 5'-GACTTGTGTAATCACAGTGG-3', RASA2_rv 5'-TACCCTGAACCTCTGAATTG-3', RASA3_fw 5'-AAGAGTGTTGAGCAGCCCAT-3', RASA3_rv 5'TAGAGAGGCTGGTCCCCTTTG-3', RASA4_fw 5'-CAGCCGGGACGACGTTATC-3', RASA4_rv 5'-CCACCCGCTGAAACCCTTAG-3', RASAL 1 _fw 5'-CGTGCTGGATGAGGACACTG-3', RASAL1_rv 5'-TCCCTGCTCAGCGAGATCTT3', RASAL2_fw 5'-CCCAACTCCATGGACACTGC-3', RASAL2_rv 5'-GGATGGAAGCCGAAAGCTCG-3', RASAL3_1_fw 5'-GGATCCAGATCGGATGCCTG-3', RASAL3_1_rv 5'-TCCCTAGAGCCCAGAGCAC-3', RASAL3_2_fw 5'-AACAGAACCGGAGACTGCTG-3', RASAL3_2_rv 5'-GCTCCAACCTGGCCTTTTTC-3', RASAL3_3_fw 5'-GCTCAAGAGGCTGAAAGAG-3', RASAL3_3_rv 5'-CAGGTCCAGTTCAGAGAGTG-3', DAB2IP_fw 5'-CATCATCAGCAGGTTGATGTCC-3', DAB2IP_rv 5'-AGCGGGCTTTTGTTTCTAATGC-3', SYNGAP1_fw 5'-ATGCAAAGCTTTAAGGAGTC-3', SYNGAP1_rv 5'-GTTCCTGATGAAGTTGTTACC-3'

\section{Targeted inhibitors}

Afatinib and Selumetinib, were purchased from Selleck Chemicals. These compounds were dissolved in dimethylsulfoxide (DMSO, Sigma-Aldrich) and stored as $10 \mathrm{mM}$ aliquots.

\section{Phenotypic drug screen and calcein green assay}

Five days after organoid trypsinization, $1 \mathrm{mg} / \mathrm{ml}$ dispase II (Invitrogen) was added to the medium of the organoids and these were incubated for $15 \mathrm{~min}$ at $37^{\circ} \mathrm{C}$ to digest the BME. Subsequently, organoids were mechanically dissociated by pipetting, filtrated using a $40 \mu \mathrm{m}$ nylon cell strainer (Falcon), resuspended in $75 \%$ $\mathrm{BME} /$ growth medium (40 organoids/ $\mu \mathrm{l}$ ) prior plating of two $10 \mu 1$ drops on Nunc ${ }^{\mathrm{TM}}$ Lab-Tek $^{\mathrm{TM}}$ II Chamber Slide ${ }^{\mathrm{TM}}$ Systems. After plating culture medium containing either $1 \mu \mathrm{M}$ of afatinib, $1 \mu \mathrm{M}$ of selumetinib, a combination of $1 \mu \mathrm{M}$ of afatinib and $1 \mu \mathrm{M}$ of selumetinib or DMSO was added. The labtek plates were mounted on an inverted confocal laser scanning microscope (Leica SP8X) and imaged using a 10X objective. For visualization of cell viability, organoids were incubated with $16.2 \mu \mathrm{M}$ Hoechst 33342 (Life Technologies) and $1.5 \mu$ M DRAQ7'TM (Cell Signaling \#7406) for $30 \mathrm{~min}$ at $37^{\circ} \mathrm{C}$ prior imaging.

For the GAP domain knock out CRISPR screen, organoids were imaged by an inverted routine microscope (Nikon Eclipse TS100) using a $4 \mathrm{X}$ or 10X objective. For calculating organoid count and size, organoids were incubated for 45 minutes with $500 \mathrm{ml}$ culture medium containing $5 \mu \mathrm{M}$ calcein-green (Invitrogen). For the quantification of the organoid size and count, FIJI analysis software was used.

\section{Author contributions}

JBP, JLB and HJGS conceived the study. JBP, HJGS designed experiments, and JBP performed most of the experiments. JBP and SE generated clones. AEEM and NH performed drug screens. JBP, AEEM, NH and HJGS analyzed and interpreted the data. JBP and HJGS wrote the manuscript, which was reviewed by all authors.

\section{ACKNOWLEDGMENTS}

We thank all members of the Snippert and Bos laboratories for fruitful discussions and support.

\section{CONFLICTS OF INTEREST}

Authors disclose no potential conflicts of interest.

\section{GRANT SUPPORT}

HJGS is supported by a KWF fellowship from the Dutch Cancer Society (UU 2013-6070), general support came from the Netherlands Organization for Scientific Research gravitation program Cancer Genomics Netherlands, the Josephine Nefkens foundation and a 'Sta op tegen Kanker' International Translational Cancer Research Grant (JLB). Stand Up to Cancer is a program administered by the AACR.

\section{REFERENCES}

1. Cunningham D, Humblet Y, Siena S, Khayat D, Bleiberg H, Santoro A, Bets D, Mueser M, Harstrick A, Verslype C, Chau I, Van Cutsem E. Cetuximab monotherapy and cetuximab plus irinotecan in irinotecan-refractory metastatic colorectal cancer. N Engl J Med. 2004; 351:337-45. https:// doi.org/10.1056/NEJMoa033025.

2. Van Cutsem E, Köhne CH, Hitre E, Zaluski J, Chang Chien CR, Makhson A, D'Haens G, Pintér T, Lim R, Bodoky G, Roh JK, Folprecht G, Ruff P, et al. Cetuximab and chemotherapy as initial treatment for metastatic colorectal cancer. N Engl J Med. 2009; 360:1408-17. https:// doi.org/10.1056/NEJMoa0805019.

3. Douillard JY, Siena S, Cassidy J, Tabernero J, Burkes R, Barugel M, Humblet Y, Bodoky G, Cunningham D, Jassem J, Rivera F, Kocákova I, Ruff P, et al. Randomized, phase III trial of panitumumab with infusional fluorouracil, leucovorin, and oxaliplatin (FOLFOX4) versus FOLFOX4 alone as firstline treatment in patients with previously untreated metastatic colorectal cancer: the PRIME study. J Clin Oncol. 2010; 28:4697-705. https://doi.org/10.1200/JCO.2009.27.4860. 
4. Masui H, Kawamoto T, Sato JD, Wolf B, Sato G, Mendelsohn J. Growth inhibition of human tumor cells in athymic mice by anti-epidermal growth factor receptor monoclonal antibodies. Cancer Res. 1984; 44:1002-07.

5. Brand TM, Iida M, Wheeler DL. Molecular mechanisms of resistance to the EGFR monoclonal antibody cetuximab. Cancer Biol Ther. 2011; 11:777-92. https://doi.org/10.4161/ cbt.11.9.15050.

6. Karapetis CS, Khambata-Ford S, Jonker DJ, O'Callaghan CJ, Tu D, Tebbutt NC, Simes RJ, Chalchal H, Shapiro JD, Robitaille S, Price TJ, Shepherd L, Au HJ, et al. K-ras mutations and benefit from cetuximab in advanced colorectal cancer. N Engl J Med. 2008; 359:1757-65. https://oi. org/10.1056/NEJMoa0804385.

7. European Medicines Agency. Erbitux: EPAR - Product Information. https://www.ema.europa.eu/documents/ product-information/erbitux-epar-product-information en.pdf. Published July 14, 2009. Updated July 19, 2017. Accessed February 11, 2019.

8. European Medicines Agency. Vectibix: EPAR - Product Information. https:/www.ema.europa.eu/documents/ product-information/vectibix-epar-product-information en.pdf. Published June 6, 2009. Updated September 11, 2018. Accessed February 11, 2019.

9. Cox AD, Der CJ. Ras history: the saga continues. Small GTPases. 2010; 1:2-27. https://doi.org/10.4161/ sgtp.1.1.12178.

10. Bos JL, Fearon ER, Hamilton SR, Verlaan-de Vries M, van Boom JH, van der Eb AJ, Vogelstein B. Prevalence of ras gene mutations in human colorectal cancers. Nature. 1987; 327:293-97. https://doi.org/10.1038/327293a0.

11. Yuen ST, Davies H, Chan TL, Ho JW, Bignell GR, Cox C, Stephens P, Edkins S, Tsui WW, Chan AS, Futreal PA, Stratton MR, Wooster R, Leung SY. Similarity of the phenotypic patterns associated with BRAF and KRAS mutations in colorectal neoplasia. Cancer Res. 2002; 62:6451-55. https://doi.org/10.1038/sj.leu.2404688.

12. Nash GM, Gimbel M, Cohen AM, Zeng ZS, Ndubuisi MI, Nathanson DR, Ott J, Barany F, Paty PB. KRAS mutation and microsatellite instability: two genetic markers of early tumor development that influence the prognosis of colorectal cancer. Ann Surg Oncol. 2010; 17:416-24. https://doi. org/10.1245/s10434-009-0713-0.

13. Misale S, Bozic I, Tong J, Peraza-Penton A, Lallo A, Baldi F, Lin KH, Truini M, Trusolino L, Bertotti A, Di Nicolantonio F, Nowak MA, Zhang L, et al. Vertical suppression of the EGFR pathway prevents onset of resistance in colorectal cancers. Nat Commun. 2015; 6:8305. https://doi.org/10.1038/ ncomms9305.

14. Misale S, Yaeger R, Hobor S, Scala E, Janakiraman M, Liska D, Valtorta E, Schiavo R, Buscarino M, Siravegna G, Bencardino K, Cercek A, Chen CT, et al. Emergence of KRAS mutations and acquired resistance to anti-EGFR therapy in colorectal cancer. Nature. 2012; 486:532-36. https://doi.org/10.1038/nature11156.

15. Diaz LA Jr, Sausen M, Fisher GA, Velculescu VE. Insights into therapeutic resistance from whole-genome analyses of circulating tumor DNA. Oncotarget. 2013; 4:1856-57. https://doi.org/10.18632/oncotarget.1486.

16. Misale S, Arena S, Lamba S, Siravegna G, Lallo A, Hobor S, Russo M, Buscarino M, Lazzari L, Sartore-Bianchi A, Bencardino K, Amatu A, Lauricella C, et al. Blockade of EGFR and MEK intercepts heterogeneous mechanisms of acquired resistance to anti-EGFR therapies in colorectal cancer. Sci Transl Med. 2014; 6:224ra26. https://doi. org/10.1126/scitranslmed.3007947.

17. Almoguera C, Shibata D, Forrester K, Martin J, Arnheim $\mathrm{N}$, Perucho M. Most human carcinomas of the exocrine pancreas contain mutant c-K-ras genes. Cell. 1988; 53:54954. https://doi.org/10.1016/0092-8674(88)90571-5.

18. Smit VT, Boot AJ, Smits AM, Fleuren GJ, Cornelisse CJ, Bos JL. KRAS codon 12 mutations occur very frequently in pancreatic adenocarcinomas. Nucleic Acids Res. 1988; 16:7773-82. https://doi.org/10.1093/nar/16.16.7773.

19. Bardelli A, Siena S. Molecular mechanisms of resistance to cetuximab and panitumumab in colorectal cancer. J Clin Oncol. 2010; 28:1254-61. https://doi.org/10.1200/ JCO.2009.24.6116.

20. De Roock W, Claes B, Bernasconi D, De Schutter J, Biesmans B, Fountzilas G, Kalogeras KT, Kotoula V, Papamichael D, Laurent-Puig P, Penault-Llorca F, Rougier P, Vincenzi B, et al. Effects of KRAS, BRAF, NRAS, and PIK3CA mutations on the efficacy of cetuximab plus chemotherapy in chemotherapy-refractory metastatic colorectal cancer: a retrospective consortium analysis. Lancet Oncol. 2010; 11:753-62. https://doi.org/10.1016/ S1470-2045(10)70130-3.

21. Bertotti A, Papp E, Jones S, Adleff V, Anagnostou V, Lupo B, Sausen M, Phallen J, Hruban CA, Tokheim C, Niknafs N, Nesselbush M, Lytle K, et al. The genomic landscape of response to EGFR blockade in colorectal cancer. Nature. 2015; 526:263-67. https://doi.org/10.1038/nature14969.

22. Misale S, Di Nicolantonio F, Sartore-Bianchi A, Siena S, Bardelli A. Resistance to anti-EGFR therapy in colorectal cancer: from heterogeneity to convergent evolution. Cancer Discov. 2014; 4:1269-80. https://doi.org/10.1158/2159-8290. CD-14-0462.

23. Medico E, Russo M, Picco G, Cancelliere C, Valtorta E, Corti G, Buscarino M, Isella C, Lamba S, Martinoglio B, Veronese $\mathrm{S}$, Siena S, Sartore-Bianchi A, et al. The molecular landscape of colorectal cancer cell lines unveils clinically actionable kinase targets. Nat Commun. 2015; 6:7002. https://doi. org/10.1038/ncomms8002.

24. Davoli T, Xu AW, Mengwasser KE, Sack LM, Yoon JC, Park PJ, Elledge SJ. Cumulative haploinsufficiency and triplosensitivity drive aneuploidy patterns and shape the cancer genome. Cell. 2013; 155:948-62. https://doi. org/10.1016/j.cell.2013.10.011. 
25. Lawrence MS, Stojanov P, Mermel CH, Robinson JT, Garraway LA, Golub TR, Meyerson M, Gabriel SB, Lander ES, Getz G. Discovery and saturation analysis of cancer genes across 21 tumour types. Nature. 2014; 505:495501. https://doi.org/10.1038/nature12912.

26. Krauthammer $\mathrm{M}$, Kong $\mathrm{Y}$, Bacchiocchi A, Evans $\mathrm{P}$, Pornputtapong N, Wu C, McCusker JP, Ma S, Cheng E, Straub R, Serin M, Bosenberg M, Ariyan S, et al. Exome sequencing identifies recurrent mutations in NF1 and RASopathy genes in sun-exposed melanomas. Nat Genet. 2015; 47:996-1002. https://doi.org/10.1038/ng.3361.

27. Hodis E, Watson IR, Kryukov GV, Arold ST, Imielinski M, Theurillat JP, Nickerson E, Auclair D, Li L, Place C, Dicara D, Ramos AH, Lawrence MS, et al. A landscape of driver mutations in melanoma. Cell. 2012; 150:251-63. https://doi. org/10.1016/j.cell.2012.06.024.

28. Nissan MH, Pratilas CA, Jones AM, Ramirez R, Won H, Liu C, Tiwari S, Kong L, Hanrahan AJ, Yao Z, Merghoub T, Ribas A, Chapman PB, et al. Loss of NF1 in cutaneous melanoma is associated with RAS activation and MEK dependence. Cancer Res. 2014; 74:2340-50. https://doi. org/10.1158/0008-5472.CAN-13-2625.

29. Maertens O, Johnson B, Hollstein P, Frederick DT, Cooper ZA, Messiaen L, Bronson RT, McMahon M, Granter S, Flaherty K, Wargo JA, Marais R, Cichowski K. Elucidating distinct roles for NF1 in melanomagenesis. Cancer Discov. 2013; 3:338-49. https://doi.org/10.1158/2159-8290. CD-12-0313.

30. Boudry-Labis E, Roche-Lestienne C, Nibourel O, Boissel N, Terre C, Perot C, Eclache V, Gachard N, Tigaud I, Plessis G, Cuccuini W, Geffroy S, Villenet C, et al, and French ALFA group. Neurofibromatosis-1 gene deletions and mutations in de novo adult acute myeloid leukemia. Am J Hematol. 2013; 88:306-11. https://doi.org/10.1002/ajh.23403.

31. Chang T, Krisman K, Theobald EH, Xu J, Akutagawa J, Lauchle JO, Kogan S, Braun BS, Shannon K. Sustained MEK inhibition abrogates myeloproliferative disease in Nf1 mutant mice. J Clin Invest. 2013; 123:335-39. https://doi. org/10.1172/JCI63193.

32. Mullally A, Ebert BL. NF1 inactivation revs up Ras in adult acute myelogenous leukemia. Clin Cancer Res. 2010; 16:4074-76. https://doi.org/10.1158/1078-0432.CCR-10-1438.

33. McGillicuddy LT, Fromm JA, Hollstein PE, Kubek S, Beroukhim R, De Raedt T, Johnson BW, Williams SM, Nghiemphu P, Liau LM, Cloughesy TF, Mischel PS, Parret A, et al. Proteasomal and genetic inactivation of the NF1 tumor suppressor in gliomagenesis. Cancer Cell. 2009; 16:44-54. https://doi.org/10.1016/j.ccr.2009.05.009.

34. Cichowski K, Santiago S, Jardim M, Johnson BW, Jacks T. Dynamic regulation of the Ras pathway via proteolysis of the NF1 tumor suppressor. Genes Dev. 2003; 17:449-54. https:// doi.org/10.1101/gad.1054703.

35. Hiatt KK, Ingram DA, Zhang Y, Bollag G, Clapp DW. Neurofibromin GTPase-activating protein-related domains restore normal growth in Nf1-/- cells. J Biol Chem. 2001; 276:7240-45. https://doi.org/10.1074/jbc.M009202200.

36. Whittaker SR, Theurillat JP, Van Allen E, Wagle N, Hsiao J, Cowley GS, Schadendorf D, Root DE, Garraway LA. A genome-scale RNA interference screen implicates NF1 loss in resistance to RAF inhibition. Cancer Discov. 2013; 3:350 62. https://doi.org/10.1158/2159-8290.CD-12-0470.

37. Van Allen EM, Wagle N, Sucker A, Treacy DJ, Johannessen CM, Goetz EM, Place CS, Taylor-Weiner A, Whittaker S, Kryukov GV, Hodis E, Rosenberg M, McKenna A, et al, and Dermatologic Cooperative Oncology Group of Germany (DeCOG). The genetic landscape of clinical resistance to RAF inhibition in metastatic melanoma. Cancer Discov. 2014; 4:94-109. https://doi.org/10.1158/2159-8290.CD-13-0617.

38. de Bruin EC, Cowell C, Warne PH, Jiang M, Saunders RE, Melnick MA, Gettinger S, Walther Z, Wurtz A, Heynen GJ, Heideman DA, Gómez-Román J, García-Castaño A, et al. Reduced NF1 expression confers resistance to EGFR inhibition in lung cancer. Cancer Discov. 2014; 4:606-19. https://doi.org/10.1158/2159-8290.CD-13-0741.

39. Campbell JD, Alexandrov A, Kim J, Wala J, Berger AH, Pedamallu CS, Shukla SA, Guo G, Brooks AN, Murray BA, Imielinski $\mathrm{M}, \mathrm{Hu} \mathrm{X}$, Ling $\mathrm{S}$, et al. Distinct patterns of somatic genome alterations in lung adenocarcinomas and squamous cell carcinomas. Nat Genet. 2016; 48:607-16. https://doi. org/10.1038/ng.3564.

40. Wells R, Birnstiel M. Kinetic complexity of chloroplastal deoxyribonucleic acid and mitochondrial deoxyribonucleic acid from higher plants. Biochem J. 1969; 112:777-86. https://doi.org/10.1042/bj1120777.

41. Zhao Z, Chen CC, Rillahan CD, Shen R, Kitzing T, McNerney ME, Diaz-Flores E, Zuber J, Shannon K, Le Beau MM, Spector MS, Kogan SC, Lowe SW. Cooperative loss of RAS feedback regulation drives myeloid leukemogenesis. Nat Genet. 2015; 47:539-43. https://doi.org/10.1038/ng.3251.

42. Grewal T, Koese M, Tebar F, Enrich C. Differential Regulation of RasGAPs in Cancer. Genes Cancer. 2011; 2:288-97. https://doi.org/10.1177/1947601911407330.

43. Sun D, Yu F, Ma Y, Zhao R, Chen X, Zhu J, Zhang CY, Chen J, Zhang J. MicroRNA-31 activates the RAS pathway and functions as an oncogenic MicroRNA in human colorectal cancer by repressing RAS p21 GTPase activating protein 1 (RASA1). J Biol Chem. 2013; 288:9508-18. https://doi. org/10.1074/jbc.M112.367763.

44. Sun D, Wang C, Long S, Ma Y, Guo Y, Huang Z, Chen X, Zhang C, Chen J, Zhang J. C/EBP- $\beta$-activated microRNA-223 promotes tumour growth through targeting RASA1 in human colorectal cancer. Br J Cancer. 2015; 112:1491-500. https://doi.org/10.1038/bjc.2015.107.

45. Gong B, Liu WW, Nie WJ, Li DF, Xie ZJ, Liu C, Liu YH, Mei P, Li ZJ. MiR-21/RASA1 axis affects malignancy of colon cancer cells via RAS pathways. World J Gastroenterol. 2015; 21:1488-97. https://doi.org/10.3748/wjg.v21.i5.1488. 
46. Mei Z, Shao YW, Lin P, Cai X, Wang B, Ding Y, Ma X, Wu X, Xia Y, Zhu D, Shu Y, Fu Z, Gu Y. SMAD4 and NF1 mutations as potential biomarkers for poor prognosis to cetuximab-based therapy in Chinese metastatic colorectal cancer patients. BMC Cancer. 2018; 18:479. https://doi. org/10.1186/s12885-018-4298-5.

47. Ohta M, Seto M, Ijichi H, Miyabayashi K, Kudo Y, Mohri D, Asaoka Y, Tada M, Tanaka Y, Ikenoue T, Kanai F, Kawabe T, Omata M. Decreased expression of the RAS-GTPase activating protein RASAL1 is associated with colorectal tumor progression. Gastroenterology. 2009; 136:206-16. https://doi.org/10.1053/j.gastro.2008.09.063.

48. Min J, Liu L, Li X, Jiang J, Wang J, Zhang B, Cao D, Yu D, Tao D, Hu J, Gong J, Xie D. Absence of DAB2IP promotes cancer stem cell like signatures and indicates poor survival outcome in colorectal cancer. Sci Rep. 2015; 5:16578. https:// doi.org/10.1038/srep16578.

49. Wan PT, Garnett MJ, Roe SM, Lee S, Niculescu-Duvaz D, Good VM, Jones CM, Marshall CJ, Springer CJ, Barford D, Marais R; Cancer Genome Project. Mechanism of activation of the RAF-ERK signaling pathway by oncogenic mutations of B-RAF. Cell. 2004; 116:855-67. https://doi.org/10.1016/ S0092-8674(04)00215-6.

50. van de Wetering M, Francies HE, Francis JM, Bounova G, Iorio F, Pronk A, van Houdt W, van Gorp J, Taylor-Weiner A, Kester L, McLaren-Douglas A, Blokker J, Jaksani S, et al. Prospective derivation of a living organoid biobank of colorectal cancer patients. Cell. 2015; 161:933-45. https:// doi.org/10.1016/j.cell.2015.03.053.

51. Saito S, Kawamura T, Higuchi M, Kobayashi T, YoshitaTakahashi M, Yamazaki M, Abe M, Sakimura K, Kanda Y, Kawamura H, Jiang S, Naito M, Yoshizaki T, et al. RASAL3, a novel hematopoietic RasGAP protein, regulates the number and functions of NKT cells. Eur J Immunol. 2015; 45:151223. https://doi.org/10.1002/eji.201444977.

52. Muro R, Nitta T, Okada T, Ideta H, Tsubata T, Suzuki H. The Ras GTPase-activating protein Rasal3 supports survival of naive T cells. PLoS One. 2015; 10:e0119898. https://doi. org/10.1371/journal.pone.0119898.

53. Scheffzek K, Ahmadian MR, Kabsch W, Wiesmüller L, Lautwein A, Schmitz F, Wittinghofer A. The Ras-RasGAP complex: structural basis for GTPase activation and its loss in oncogenic Ras mutants. Science. 1997; 277:333-8. https:// doi.org/10.1126/science.277.5324.333.

54. Ahmadian MR, Kiel C, Stege P, Scheffzek K. Structural fingerprints of the Ras-GTPase activating proteins neurofibromin and p120GAP. J Mol Biol. 2003; 329:699710. https://doi.org/10.1016/S0022-2836(03)00514-X.

55. Drost J, van Jaarsveld RH, Ponsioen B, Zimberlin C, van Boxtel R, Buijs A, Sachs N, Overmeer RM, Offerhaus GJ, Begthel H, Korving J, van de Wetering M, Schwank G, et al. Sequential cancer mutations in cultured human intestinal stem cells. Nature. 2015; 521:43-47. https://doi.org/10.1038/ nature14415.
56. King PD, Lubeck BA, Lapinski PE. Nonredundant functions for Ras GTPase-activating proteins in tissue homeostasis. Sci Signal. 2013; 6:re1. https://doi.org/10.1126/ scisignal.2003669.

57. Bollen Y, Post J, Koo BK, Snippert HJ. How to create stateof-the-art genetic model systems: strategies for optimal CRISPR-mediated genome editing. Nucleic Acids Res. 2018; 46:6435-54. https://doi.org/10.1093/nar/gky571.

58. Verissimo CS, Overmeer RM, Ponsioen B, Drost J, Mertens S, Verlaan-Klink I, Gerwen BV, van der Ven M, Wetering MV, Egan DA, Bernards R, Clevers H, Bos JL, Snippert HJ. Targeting mutant RAS in patient-derived colorectal cancer organoids by combinatorial drug screening. Elife. 2016; 5:1-26. https://doi.org/10.7554/eLife.18489.

59. Ahronian LG, Corcoran RB. Effective MAPK Inhibition is critical for therapeutic responses in colorectal cancer with BRAF mutations. Mol Cell Oncol. 2015; 3:e1048405. https:// doi.org/10.1080/23723556.2015.1048405.

60. Min J, Zaslavsky A, Fedele G, McLaughlin SK, Reczek EE, De Raedt T, Guney I, Strochlic DE, Macconaill LE, Beroukhim R, Bronson RT, Ryeom S, Hahn WC, et al. An oncogene-tumor suppressor cascade drives metastatic prostate cancer by coordinately activating Ras and nuclear factor-kappaB. Nat Med. 2010; 16:286-94. https://doi. org/10.1038/nm.2100.

61. Arafeh R, Qutob N, Emmanuel R, Keren-Paz A, Madore J, Elkahloun A, Wilmott JS, Gartner JJ, Di Pizio A, WinogradKatz S, Sindiri S, Rotkopf R, Dutton-Regester K, et al. Recurrent inactivating RASA2 mutations in melanoma. Nat Genet. 2015; 47:1408-10. https://doi.org/10.1038/ng.3427.

62. Liu D, Yang C, Bojdani E, Murugan AK, Xing M. Identification of RASAL1 as a major tumor suppressor gene in thyroid cancer. J Natl Cancer Inst. 2013; 105:1617-27. https://doi.org/10.1093/jnci/djt249.

63. Calvisi DF, Ladu S, Conner EA, Seo D, Hsieh JT, Factor VM, Thorgeirsson SS. Inactivation of Ras GTPase-activating proteins promotes unrestrained activity of wild-type Ras in human liver cancer. J Hepatol. 2011; 54:311-19. https://doi. org/10.1016/j.jhep.2010.06.036.

64. Huang Y, Zhao M, Xu H, Wang K, Fu Z, Jiang Y, Yao Z. RASAL2 down-regulation in ovarian cancer promotes epithelial-mesenchymal transition and metastasis. Oncotarget. 2014; 5:6734-45. https://doi.org/10.18632/oncotarget.2244.

65. McLaughlin SK, Olsen SN, Dake B, De Raedt T, Lim E, Bronson RT, Beroukhim R, Polyak K, Brown M, Kuperwasser C, Cichowski K. The RasGAP gene, RASAL2, is a tumor and metastasis suppressor. Cancer Cell. 2013; 24:365-78. https://doi.org/10.1016/j.ccr.2013.08.004.

66. Philpott C, Tovell H, Frayling IM, Cooper DN, Upadhyaya M. The NF1 somatic mutational landscape in sporadic human cancers. Hum Genomics. 2017; 11:13. https://doi. org/10.1186/s40246-017-0109-3.

67. Yap YS, McPherson JR, Ong CK, Rozen SG, Teh BT, Lee AS, Callen DF. The NF1 gene revisited - from bench 
to bedside. Oncotarget. 2014; 5:5873-92. https://doi. org/10.18632/oncotarget.2194.

68. Stites EC, Trampont PC, Haney LB, Walk SF, Ravichandran KS. Cooperation between Noncanonical Ras Network Mutations. Cell Rep. 2015 Jan 15. https://doi.org/10.1016/j. celrep.2014.12.035. [Epub ahead of print].

69. Stowe IB, Mercado EL, Stowe TR, Bell EL, Oses-Prieto JA, Hernández H, Burlingame AL, McCormick F. A shared molecular mechanism underlies the human rasopathies Legius syndrome and Neurofibromatosis-1. Genes Dev. 2012; 26:1421-26. https://doi.org/10.1101/gad.190876.112.

70. Li S, Nakamura S, Hattori S. Activation of R-Ras GTPase by GTPase-activating proteins for ras, gap1(m), and p120GAP.
J Biol Chem. 1997; 272:19328-32. https://doi.org/10.1074/ jbc.272.31.19328.

71. Sung H, Kanchi KL, Wang X, Hill KS, Messina JL, Lee JH, Kim Y, Dees ND, Ding L, Teer JK, Yang S, Sarnaik AA, Sondak VK, et al. Inactivation of RASA1 promotes melanoma tumorigenesis via R-Ras activation. Oncotarget. 2016; 7:23885-96. https://doi.org/10.18632/oncotarget.8127.

72. Lapinski PE, Kwon S, Lubeck BA, Wilkinson JE, Srinivasan RS, Sevick-Muraca E, King PD. RASA1 maintains the lymphatic vasculature in a quiescent functional state in mice. J Clin Invest. 2012; 122:733-47. https://doi.org/10.1172/JCI46116. 